\title{
Exercise Promotion: Reviewing the Importance of Health Professionals' Interpersonal Behaviors on Exercisers' Basic Psychological Needs
}

Perceptual and Motor Skills 202I, Vol. I28(2) 800-812

(C) The Author(s) 2020

Article reuse guidelines: sagepub.com/journals-permissions DOI: 10.1 |77/003 |5|2520983078 journals.sagepub.com/home/pms

@SAGE

\section{Filipe Rodrigues $^{1,2}$ (1) and Rita Macedo ${ }^{3}$}

\begin{abstract}
Previous studies have investigated the impact of exercisers' perceptions of health professionals' interpersonal behaviors on exercisers' exercise adherence. From these studies, there is increased interest in developing and evaluating programs to improve health professionals' communication skills and interpersonal behavior. In this narrative review, we provide examples of self-determination theory and newer modifications to it, discuss the empirical conditions that foster optimal exerciser motivation, consider the antecedent factors influencing health professionals' behaviors, and offer practical suggestions to health professionals seeking to promote regular exercise practice. Since exercisers perceive and differentiate health professionals' need-supportive, need-thwarting, and need-passive behaviors, health professionals who can critically and consciously distinguish these different types of behavior are more likely to foster supportive climates and suppress the use of need-thwarting and need-indifferent behaviors. The interpersonal interaction between health professionals and exercisers strongly influences how exercisers will regulate their behavior toward persistent exercise.
\end{abstract}

\footnotetext{
'Sport Science School of Rio Maior (ESDRM—IPSantarém), Rio Maior, Portugal

${ }^{2}$ Life Quality Research Center (CIEQV), Santarém, Portugal

${ }^{3}$ Center for Organizational and Social Studies of P. PORTO, Porto, Portugal
}

\section{Corresponding Author:}

Filipe Rodrigues, Sport Science School of Rio Maior, Av. Dr. Mário Soares n I 10, Rio Maior, Portugal.

Email: ptfiliperodrigues@gmail.com 


\section{Keywords}

need-supportive, need-thwarting, need-indifference, health promotion, physical activity

\section{Introduction}

Health professionals have been identified as key influencers of whether or how exercise trainees engage in physical activity (PA) as described by Teixeira et al. (2012). Personal characteristics such as the health professional's enthusiasm, communication skills, health-related knowledge (Edmunds et al., 2008), and the exerciser's enjoyment during exercise participation (Wininger, 2002) have been shown to impact exercisers' adherence to PA. In addition, health professionals who express beliefs that every person is able to practice PA and achieve positive outcomes contribute positively to PA encouragement (Ntoumanis et al., 2017). Thus, health professionals' behavior and interpersonal relationships with exercisers are apt to increase the exercisers' intrinsic motivation, ultimately translating into higher rates of exercise persistence (Rodrigues et al., 2018). These discoveries highlight a need to examine social context features in the health professional-exerciser relationship that are most closely associated with the exercisers' self-regulatory processes and regular exercise practice.

\section{Theoretical Background}

In the PA context, understanding what type of motivation an individual experiences can greatly assist efforts to promote exercise behavior (Hagger \& Chatzisarantis, 2008). Self-determination theory (SDT; Ryan \& Deci, 2017) is a contemporary approach among theories of human motivation. Ryan and Deci (2017) suggested that behaviors can be based on autonomous motivation (i.e., engaging in a behavior because of self-will or perceived pleasure), controlled motivation (i.e., performing a behavior for external-rewards or perceived approval from others) or they can be amotivated (i.e., lacking or willingness to engage in a behavior). The social context might support or thwart selfregulated behaviors and might largely predict how autonomously regulated one's behavior is likely to be. Thus, social interactions between exercisers and health professionals impact the exercisers' motivation. More specifically, social interactions that contribute to exercisers' basic psychological needs - namely, autonomy, competence, and relatedness (Vansteenkiste \& Ryan, 2013) - are apt to have the most positive behavioral impact.

In the Ryan and Deci (2017) model, autonomy satisfaction refers to the alignment between self-controlled actions and personal values. Competence satisfaction depicts feelings of effectiveness and skill mastery. Relatedness 
satisfaction represents the feeling of personal bonding and caring by others. On the other hand, autonomy frustration represents the feeling of self-imposed or external pressures to act contrarily to one's own will. Competence frustration depicts feelings of failure and doubts about self-efficacy. Relatedness frustration refers to feelings of disconnection, loneliness and social exclusion. Satisfying all three basic psychological needs (i.e., autonomy, competence, and relatedness) contributes to personal growth and elicits positive outcomes (Deci \& Ryan, 1985). However, people in leadership positions may, instead, control human behavior and thwart these needs, leading to negative outcomes (Ryan \& Deci, 2017).

In the context of the current literature review, health professionals play the key leadership role in the trainer-exerciser relationship, and their behavior can influence the development of autonomous and/or controlled forms of motivation and amotivation, by actively satisfying or frustrating the exercisers' basic psychological needs (Rodrigues et al., 2018; Teixeira et al., 2012). Exercisers who perceive health professionals as need-supportive are more likely to experience needs satisfaction and display autonomous motivation (Teixeira et al., 2012), while those who perceive need-thwarting behaviors from exercise physiologists and other health professionals are more apt to experience needs frustration, resulting in higher levels of controlled motivation or amotivation (Rodrigues et al., 2018).

Grounded within SDT, the current review will focus on health professionals' use of need-supportive, need-thwarting, and need-indifferent interpersonal behaviors. While need-supportive behaviors (mainly autonomy-supportive behaviors) have been examined in the SDT literature, comparatively little research in the exercise context has focused on the need-thwarting behaviors (sometimes characterized as controlling) displayed by health professionals. Evidence from contemporary literature will be briefly presented in this review, alongside existing evidence from similar contexts (i.e., sports and physical education) in order to highlight how health professionals can engage in different interpersonal behaviors that positively influence exercisers' basic psychological needs. We hope that by providing empirically based examples of these interpersonal behaviors, we can elucidate their possible positive and negative consequences for exercisers.

\section{Need-Supportive Behaviors}

Individuals who perceive health professionals as need-supportive figures are more likely to experience higher levels of needs satisfaction (Puente \& Anshel, 2010; Rodrigues et al., 2020; Quested \& Duda, 2010). Hence, health professionals should foster a supportive environment for trainees to experience increased autonomous motivation. Recent evidence suggests that higher levels of autonomous motivation are associated with PA adherence (Gomes et al., 2018), 
enjoyment (Rodrigues et al., 2020), positive affect (Teixeira et al., 2018), and well-being ( $\mathrm{Ng}$ et al., 2013).

An example might serve to illustrate these points. Imagine that Karen is a young exerciser who has been training for the last four months with James, a certified personal trainer. She feels energized when exercising and recognizes its importance. Since the first training session, Karen has actively perceived James as attentive and focused on her wellbeing. In addition, James gives Karen the opportunity to control the training session by selecting the exercises she most enjoys. Karen's perception of autonomy support from James has led her to experience autonomy satisfaction. Additionally, James plans challenging training sessions so that Karen acquires new abilities, and constantly gives her constructive and positive feedback whenever she improves her skills. Karen perceives James as a need-supportive person, and she therefore experiences higher levels of competence satisfaction. She perceives James as empathic person and has developed an emotional bond with him, assuring a professional connection of confidence and respect. James' relatedness-supportive behavior, as perceived by Karen, has led her to experience relatedness satisfaction. This perception of need-supportive behaviors and the satisfaction of Karen's basic psychological needs has led her to exercise more, and it and has amplified her autonomous drive to engage in PA. If James continues to foster these active need-supportive behaviors, Karen will likely maintain exercise participation over a long time.

\section{Need-Thwarting Behaviors}

Alternatively, people in leadership positions might also behave in a controlling, pressuring and forced manner, imposing preconceived ideas or feelings (Van den Broeck et al., 2016). Previous studies have suggested that exercisers who perceive need-thwarting behaviors from health professionals are more prone to experience needs frustration (Rodrigues et al., 2020). Needs frustration, in turn, has been positively correlated with controlled motivation (Moreno-Murcia et al., 2018), and existing literature in the exercise context has shown that controlled motivation significantly predicts depressive symptoms, low levels of self-esteem (Ng et al., 2013), weaker exercise intentions (Rodrigues et al., 2019), higher levels of negative affect (Teixeira et al., 2018), and lower self-reported time spent in weekly moderate and vigorous exercise (Teixeira et al., 2012).

To exemplify the relationship between need-thwarting behaviors and needs frustration, imagine Michael, a 20-year old exerciser who has received a free training session in a new health and fitness center. As he is passionate about mountain biking, Michael decides to try John's indoor cycling class. After a few classes, John starts to impose higher workloads, and he pressures Michael to pedal faster. Michael starts to feel that he does not control his behavior during the training, and he is not free to select his own workout intensity. 
His perception of need-thwarting behaviors leads Michael to experience autonomy frustration. In addition, John constantly verbalizes his doubts in Michael's capacity to improve, discourages him from trying advanced movements and gives negative feedback. These competence-thwarting behaviors lead Michael to experience competence frustration while exercising. John also lacks empathy and does not connect with Michael. Michael's perception of John's relatedness thwarting leads him to experience relatedness frustration. According to SDT theory, this frustration of needs is associated with controlled regulation towards John's behavior, meaning that sooner or later, Michael will only go to group classes because of external pressures (e.g., John constantly saying "if you want to lose weight, you must go to all of my indoor cycling classes") or internal obligations (e.g., Michael talking to himself saying "If I do not go to the next class, I will not lose weight and John will get upset"). Over the long run, this controlled and/or amotivated behavior is likely to decrease Michael's intention to exercise, ultimately leading Michael to withdraw from exercise (Rodrigues et al., 2020).

\section{Perceived Need-Indifferent and Passive Behaviors}

Recently, several researchers have addressed a third type of perceived interpersonal behavior related to a third type of human needs. Bhavsar et al. (2019) suggested conceptually distinguishing between a leader's active behaviors and behaviors that are "indifferent" or "absent" to how a follower's psychological needs are met. These authors argue that unresponsiveness or passive behavior from an individual's social environment could elicit autonomy indifference (i.e., a feeling of disinterest in the perspectives, preferences and opinions displayed by the person in authority), competence indifference (i.e., a feeling of unresponsiveness or negligence in creating conditions that will foster progress) and relatedness indifference (i.e., a feeling of apathy or inattentiveness from the person in authority). Quested et al. (2018) made a case that need indifferent behaviors are empirically different from either active need-supportive or need-thwarting behaviors, and from exercisers' perceptions of passive behaviors. Quested et al. (2018) asserted that they had "personally experienced and also observed exercise class instructors employing ongoing rhetoric throughout class that lacked qualities that would support or thwart autonomy, competence, or relatedness" (p. 261).

Bhavsar et al. (2019) concluded that perceived need-indifference behaviors are also associated with needs frustration and, to a lesser extent, with perceived need-thwarting behaviors. Cheon et al. (2019) suggested that social agents (i.e., leaders) might adopt need-indifferent behaviors because they are more attentive to their own needs than to those of others. Thus, perceived indifference is associated with followers' autonomy-indifference. Even though this review does not focus heavily on the leader's personality characteristics, an understanding of a health professional's personality (e.g., narcissism) might provide additional 
insights on how and when they behave in either a passive or active manner. For example, Nevicka et al. (2018) found narcissistic leaders to be perceived as abusive and controlling, contributing to the followers' lower levels of selfesteem. Moreover, in work settings, passive behavior from people in higher hierarchical positions has been seen as contributing to the degradation of employees' mental health, a decrease in their work attitude (Barling \& Frone, 2017) and a deterioration of emotional outcomes such as trust (Adeel et al., 2018). All in all, these studies suggest an association between passive behaviors and negative outcomes. Active and passive health professionals' interpersonal behaviors might thwart, satisfy or be indifferent to exercisers needs and might co-occur in each context, and, over time.

Going back to the previous example of the trainer-exerciser relationship between John and Michael, if John displayed passive behavior during indoor cycling classes, he might offer Michael non-meaningful choices. John might not either discourage or encourage Michael to increase pedal load or to pedal faster. John might not search for social interaction opportunities with Michael, or he might speak to Michael in a "motivationally empty" way. According to this newer conception, Michael would likely perceive John's behavior as indifferent, and this would likely lead to negative outcomes, such as Michael's needs frustration.

\section{Antecedent Influences on Health Professional Behaviors}

Until now, research has focused on how exercisers' perceptions of active and passive behaviors influenced their needs. However, it seems of equal importance to also wonder about and strive to uncover the reasons why health professionals interact with exercisers in a certain way. Although some past studies have found a significant association between motivational antecedents and behavior outcomes, deeper research on this topic is needed.

According to Ryan and Deci (2017), interpersonal behavior styles are the result of a person's motivational regulation (i.e., autonomous or controlled) within the context (Pelletier et al., 2002; Rocchi \& Pelletier, 2017). For instance, in supportive contexts, sport coaches report increased levels of autonomous motivation, leading to their higher reported supportive interpersonal behaviors. On the other hand, when the context frustrates coaches' psychological needs, coaches experience controlled motivation and, as a consequence, engage in need thwarting interpersonal behaviors (Rocchi \& Pelletier, 2017). Several contextual factors such as opportunities for professional development and job security (Stebbings et al., 2012); and colleague support, time constraints, and administrative support (Rocchi \& Pelletier, 2017); and social desirability (Stebbings et al., 2011) might predict trainers' psychological needs satisfaction and/or frustration. In a qualitative study by Allen and Shaw (2009), competence development opportunities, organizational support, and sense of coaching relatedness 
were pinpointed as relevant factors influencing coaches' needs satisfaction. In classroom teaching, similar antecedents have been identified, namely job pressure, students' self-determined motivation (Taylor et al., 2008), work constraints (Pelletier et al., 2002) and teachers' evaluations by self and others (Taylor et al., 2009).

Recent studies (Ntoumanis et al., 2018; Thogersen-Ntoumani \& Ntoumanis, 2007) have shown that health professionals were more autonomously motivated to instruct and were perceived as more autonomy-supportive when exercisers were portrayed as having autonomous rather than controlled motivation. On the other hand, these health professionals reported higher levels of controlled motivation and need-thwarting behaviors when presented with overweight versus normal weight exercisers. These authors suggested that perceptions of an individual's motivation and their body weight status can impact health professionals' motivation to instruct and to interact with the exerciser. Health professionals who expressed beliefs that exercisers are able to achieve positive outcomes were more likely to display more autonomous motivation (Ntoumanis et al., 2018). Health professionals are influenced by several contextual factors from "above" (e.g., administration pressure), "below" (e.g., exercisers aspirations and behavioral regulations), "in line" (e.g., colleagues support), self-perception (e.g., time constraints), and/or others-perception (e.g., social recognition, affiliation). Understanding the reasons behind health professionals' behavior could provide crucial insights into efforts to design effective techniques for helping health professionals to be perceived by exercisers as supportive. As it stands, there are relatively few studies examining these precursors of health professionals' behaviors towards exercisers.

\section{Practical Implications for Health Professionals}

Table 1 presents examples of how health professionals should communicate with PA participants, to influence participants' perception of need-supportive behaviors. Definitions and examples of how health professionals should avoid needthwarting behaviors are also shown in Table 1. These guidelines are based on past literature reports (Gilbert et al., 2017; Quested et al., 2017; Smith \& Smoll, 2017). Health professionals should be self-aware of whether they actively or passively conduct training sessions and are or are not demonstrating interest in how they are perceived by PA participants. As past literature advises, individuals in key positions should engage in active and positive ways so that individuals perceive them as supportive and caring. More studies are needed to outline the importance of effective interpersonal communications in the trainer-exerciser relationship. 
Table I. Examples of Need-Supporting and Thwarting Behaviors for Health Professionals.

\begin{tabular}{|c|c|c|}
\hline & Definition & Examples \\
\hline $\begin{array}{l}\text { Need-supportive } \\
\text { behaviors }\end{array}$ & $\begin{array}{l}\text { The perception of strate- } \\
\text { gies that people in key } \\
\text { positions adopt to } \\
\text { stimulate their fol- } \\
\text { lowers' learning pro- } \\
\text { cess, self-determined } \\
\text { motivation and person- } \\
\text { al development. }\end{array}$ & $\begin{array}{l}\text { Let individuals know that you appreciate } \\
\text { and value their efforts. } \\
\text { Look for positive things, such as small } \\
\text { increases in workloads, capacities and } \\
\text { skills. } \\
\text { Give positive feedback, emphasizing the } \\
\text { good things, providing corrective } \\
\text { instructions, explaining where they failed } \\
\text { and how they can improve. } \\
\text { Help new participants integrating with } \\
\text { current members and promote a climate } \\
\text { of exchange to encourage social bonds. } \\
\text { Express passionate attitude towards phys- } \\
\text { ical activity and connect with the } \\
\text { participants. } \\
\text { Vary and adapt exercises to individual's } \\
\text { needs, creating a stimulating environ- } \\
\text { ment during each training session. } \\
\text { Reinforce hard work as much as outcomes. } \\
\text { Try to structure physical activity as a } \\
\text { learning-oriented experience in which } \\
\text { you are going to help them become the } \\
\text { best they can be } \\
\text { Give technical instruction by establishing a } \\
\text { competent and professional role. } \\
\text { Encourage the learning and improvement } \\
\text { of new skills and avoid focusing on } \\
\text { results (e.g. aesthetics). } \\
\text { Reward improvement, progress and effort. }\end{array}$ \\
\hline $\begin{array}{l}\text { Need-thwarting } \\
\text { behaviors }\end{array}$ & $\begin{array}{l}\text { The perception of feeling } \\
\text { controlled by people in } \\
\text { key positions and } \\
\text { experiencing sup- } \\
\text { pressed autonomy and } \\
\text { non-self-regulated } \\
\text { behavior. }\end{array}$ & $\begin{array}{l}\text { Express negative feedback. } \\
\text { Discourage people from trying more diffi- } \\
\text { cult tasks. } \\
\text { Employing intimidating language and coer- } \\
\text { cive conducts. } \\
\text { Use conditional regards or external } \\
\text { rewards. } \\
\text { Compare exercisers physical fitness or } \\
\text { appearance. } \\
\text { Define success as outperforming other } \\
\text { exercisers. } \\
\text { Punish mistakes and errors. }\end{array}$ \\
\hline
\end{tabular}




\section{Agenda for Future Research}

This brief narrative review emphasized advances in theory and research concerning the impact of a leader's interpersonal behaviors on a follower's psychological needs as applied to health professionals and exercise trainees. Some suggestions for forthcoming studies that will advance this literature might contribute to the creation of effective strategies that health professionals could use in their efforts to promote long-term exercise adherence.

First, there is a paramount need for more research assessing exercisers' feelings of dissatisfaction and how these feelings may be associated with perceived active and passive health professional behaviors. Little is known about the impact of passive behaviors on basic needs (Cheon et al., 2019), but understanding the way exercisers perceive active and passive behaviors from health professionals might yield relevant insights for preventing negative outcomes such as exercise dropout. Additionally, numerous studies on interpersonal behaviors have focused on exercisers' perception of health professionals' behaviors, leaving abundant room for progress in understanding health professionals' perception of exercisers' behaviors. By the same token, literature evaluating the antecedent conditions that underlie health professionals' behavior remains scarce. Hence, many questions remain concerning what factors influence active need-supportive, need-thwarting and passive health professional behaviors.

\section{Conclusion}

We hope that our efforts to identify and discuss the interpersonal behaviors associated with exercisers' basic psychological needs will be helpful in future cross-sectional and experimental research. Overall, the literature on interpersonal behaviors highlights adaptive outcomes associated with need-supportive leadership and maladaptive outcomes from need-thwarting and need-indifferent leadership behavior. Grounded in SDT, this review has evidenced distinctive beneficial interpersonal behavior in the exercise context, including recent advances in basic psychological need theory over the recent years. Additionally, this review provided empirically based examples of helpful and unhelpful interpersonal behaviors from health professionals in the exercise context.

We intended this narrative review to summarize evidence for theoretical breakthroughs in the study of interpersonal leader-follower behavior and motivation. We highlighted the need for health professionals to connect with exercisers to promote autonomous motivation for positive health-related outcomes such as exercise adherence. Health professionals should encourage exercisers to improve technique and challenge themselves while also providing them some volitional choice concerning the exercises to perform. In addition, health professionals should aim at relating to and getting to know the individuals they 
train so as to promote social bonding and foster a positive environment. Understanding the aspirations underlying individual motivation is essential for effectively training people. Considering all these might help in selecting optimal strategies to support participants' self-determined PA. Negative feedback, imposed pressure, and controlled demands to follow programmed training sessions should be avoided. These need-thwarting behaviors forecast trainees 'controlled motivation and negative outcomes. Indifferent behaviors are also related to trainees' need frustration, dissatisfaction and negative emotional outcomes. Passive behaviors can be ineffective for promoting autonomy, competence, and relatedness satisfaction, and lack of attention is undesirable for promoting long-term PA. Each trainee is unique, and differences arise between their genders, ages, and personal preferences (Ryan \& Deci, 2017) so that each trainee requires a different interpersonal approach guided by these broad themes.

\section{Competing Interests}

No conflicts to declare.

\section{Acknowledgments}

This work was supported by the Portuguese Foundation for Science and Technology (number UIDP/04748/2020).

\section{Declaration of Conflicting Interests}

The author(s) declared no potential conflicts of interest with respect to the research, authorship, and/or publication of this article.

\section{Funding}

The author(s) received no financial support for the research, authorship, and/or publication of this article.

\section{ORCID iD}

Filipe Rodrigues (D) https://orcid.org/0000-0003-1327-8872

\section{References}

Adeel, M. M., Khan, H. G. A., Zafar, N., \& Rizvi, S. T. (2018). Passive leadership and its relationship with organizational justice: Verifying mediating role of affect-based trust. Journal of Management Development, 37(2), 212-223. https://doi.org/10.1108/JMD05-2017-0187

Allen, J., \& Shaw, S. (2009). Women coaches' perceptions of their sport organizations' social environment: Supporting coaches' psychological needs? The Sport Psychologist, 23(3), 346-366. https://doi.org/10.1123/tsp.23.3.346 
Barling, J., \& Frone, M. (2017). If only my leader would just do something! passive leadership undermines employee well-being through role stressors and psychological resource depletion. Stress and Health: Journal of the International Society for the Investigation of Stress, 33(3), 211-222. https://doi.org/10.1002/smi.2697

Bhavsar, N., Ntoumanis, N., Quested, E., Gucciardi, D., Thøgersen-Ntoumani, C., Ryan, R., Reeve, J., Sarrazin, P., \& Bartholomew, K. (2019). Conceptualizing and testing a new tripartite measure of coach interpersonal behaviors. Psychology of Sport and Exercise, 44, 107-120. https://doi.org/10.31234/osf.io/enj5w

Cheon, S., Reeve, J., Lee, Y., Ntoumanis, N., Gillet, N., Kim, B., \& Song, Y. (2019). Expanding autonomy psychological need states from two (satisfaction, frustration) to three (dissatisfaction): A classroom-based intervention study. Journal of Educational Psychology, 111(4), 685-702. https://doi.org/10.1037/edu0000306

Deci, E., \& Ryan, R. (1985). Intrinsic motivation and Self-Determination in human behavior. Guilford Press.

Edmunds, J., Ntoumanis, N., \& Duda, J. (2008). Testing a self-determination theorybased teaching style intervention in the exercise domain. European Journal of Social Psychology, 38(2), 375-388. https://doi.org/10.1002/ejsp.463

Gilbert, M., Chaubet, P., Karelis, A., \& Dancause, K. N. (2017). Perceptions of group exercise courses and instructors among Quebec adults. BMJ Open Sport and Exercise Medicine, 3(1), e000278. https://doi.org/10.1136/bmjsem-2017-000278

Gomes, A., Gonçalves, A., Maddux, J., \& Carneiro, L. (2018). The intention-behaviour gap: An empirical examination of an integrative perspective to explain exercise behaviour. International Journal of Sport and Exercise Psychology, 16(6), 607-621. https:// doi.org/10.1080/1612197x.2017.1321030

Hagger, M., \& Chatzisarantis, N. (2008). Self-determination theory and the psychology of exercise. International Review of Sport and Exercise Psychology, 1(1), 79-103. https://doi.org/10.1080/17509840701827437

Moreno-Murcia, J., Huescar Hernandez, E., \& Ruiz, L. (2018). Perceptions of controlling teaching behaviors and the effects on the motivation and behavior of high school physical education students. International Journal of Environmental Research and Public Health, 15(10), 2288. https://doi.org/10.3390/ijerph15102288

Nevicka, B., De Hoogh, A., Den Hartog, D., \& Belschak, F. (2018). Narcissistic leaders and their victims: Followers low on Self-Esteem and low on core Self-Evaluations suffer most. Frontiers in Psychology, 9, 422. https://doi.org/10.3389/fpsyg.2018.00422

Ng, J. Y., Ntoumanis, N., Thøgersen-Ntoumani, C., Stott, K., \& Hindle, L. (2013). Predicting psychological needs and well-being of individuals engaging in weight management: The role of important others. Applied Psychology. Health and Well-Being, 5(3), 291-310. https://doi.org/10.1111/aphw.12011

Ntoumanis, N., Guerrero, M., Gadeke, C., \& Thogersen-Ntoumani, C. (2018). Do exerciser weight status and perceived motivation predict instructors' motivation and beliefs about the exerciser? A test of motivation contagion effects. Body Image, 26, 10-18. https://doi.org/10.1016/j.bodyim.2018.05.001

Ntoumanis, N., Thogersen-Ntoumani, C., Quested, E., \& Hancox, J. (2017). The effects of training group exercise class instructors to adopt a motivationally adaptive communication style. Scandinavian Journal of Medicine \& Science in Sports, 27(9), 1026-1034. https://doi.org/10.1111/sms.12713 
Pelletier, L., Séguin-Lévesque, C., \& Legault, L. (2002). Pressure from above and pressure from below as determinants of teachers' motivation and teaching behaviors. Journal of Educational Psychology, 94(1), 186-196. https://doi.org/10.1037/00220663.94.1.186

Puente, R., \& Anshel, M. (2010). Exercisers' perceptions of their fitness instructor's interacting style, perceived competence, and autonomy as a function of selfdetermined regulation to exercise, enjoyment, affect, and exercise frequency. Scandinavian Journal of Psychology, 51(1), 38-45. https://doi.org/10.1111/j.14679450.2009.00723.x

Teixeira, D., Silva, M. \& Palmeira, A. (2018). How does frustration make you feel? A motivational analysis in exercise context. Motivation and Emotion, 42, 419-428. https://doi.org/10.1007/s11031-018-9690-6.

Quested, E., \& Duda, J. (2010). Exploring the social-environmental determinants of welland ill-being in dancers: A test of basic needs theory. Journal of Sport \& Exercise Psychology, 32(1), 39-60.

Quested, E., Ntoumanis, N., Stenling, A., Thogersen-Ntoumani, C., \& Hancox, J. E. (2018). The Need-Relevant instructor behaviors scale: Development and initial validation. Journal of Sport \& Exercise Psychology, 40(5), 259-268. https://doi.org/10. 1123/jsep.2018-0043

Quested, E., Ntoumanis, N., Thøgersen-Ntoumani, C., Hagger, M., \& Hancox, J. (2017). Evaluating quality of implementation in physical activity interventions based on theories of motivation: Current challenges and future directions. International Review of Sport and Exercise Psychology, 10(1), 252-269. https://doi.org/10.1080/1750984x. 2016.1217342

Rocchi, M., \& Pelletier, L. (2017). The antecedents of coaches' interpersonal behaviors: The role of the coaching context, coaches' psychological needs, and coaches' motivation. Journal of Sport \& Exercise Psychology, 39(5), 366-378. https://doi.org/10.1123/ jsep.2016-0267

Rodrigues, F., Bento, T., Cid, L., Neiva, H., Teixeira, D., Moutao, J., Marinho, D., \& Monteiro, D. (2018). Can interpersonal behavior influence the persistence and adherence to physical exercise practice in adults? A systematic review. Frontiers in Psychology, 9, 2141. https://doi.org/10.3389/fpsyg.2018.02141

Rodrigues, F., Teixeira, D. S., Cid, L., Machado, S., \& Monteiro, D. (2019). The role of dark-side of motivation and intention to continue in exercise: A self-determination theory approach. Scandinavian Journal of Psychology, 60(6), 585-595. https://doi.org/ $10.1111 /$ sjop. 12582

Rodrigues, F., Teixeira, D., Neiva, H., Cid, L., \& Monteiro, D. (2020). The bright and dark sides of motivation as predictors of enjoyment, intention, and exercise persistence. Scandinavian Journal of Medicine \& Science in Sports, 30(4), 787-800. https:// doi.org/10.1111/sms.13617

Ryan, R., \& Deci, E. (2017). Self-determination theory. Basic psychological needs in motivation, development, and wellness. Guilford Press.

Smith, R., \& Smoll, F. (2017). Coaching behavior and effectiveness in sport and exercise psychology. In: C. Bruns (Ed.), Oxford research encyclopedias. Oxford University Press. https://doi.org/10.1093/acrefore/9780190236557.013.188 
Stebbings, J., Taylor, I., \& Spray, C. (2011). Antecedents of perceived coach autonomy supportive and controlling behaviors: Coach psychological need satisfaction and wellbeing. Journal of Sport \& Exercise Psychology, 33(2), 255-272. https://doi.org/10. $1123 /$ jsep.33.2.255

Stebbings, J., Taylor, I., Spray, C., \& Ntoumanis, N. (2012). Antecedents of perceived coach interpersonal behaviors: The coaching environment and coach psychological well- and ill-being. Journal of Sport \& Exercise Psychology, 34(4), 481-502. https://doi. org/10.1123/jsep.34.4.481

Taylor, I., Ntoumanis, N., \& Smith, B. (2009). The social context as a determinant of teacher motivational strategies in physical education. Psychology of Sport and Exercise, 10(2), 235-243. https://doi.org/10.1016/j.psychsport.2008.09.002

Taylor, I., Ntoumanis, N., \& Standage, M. (2008). A Self-Determination theory approach to understanding the antecedents of teachers' motivational strategies in physical education. Journal of Sport \& Exercise Psychology, 30(1), 75-94. https:// doi.org/10.1123/jsep.30.1.75

Teixeira, P., Carraca, E., Markland, D., Silva, M., \& Ryan, R. (2012). Exercise, physical activity, and self-determination theory: A systematic review. International Journal of Behavioral Nutrition \& Physical Activity, 9, 78. https://doi.org/10.1186/1479-5868-9-78

Thogersen-Ntoumani, C., \& Ntoumanis, N. (2007). A self-determination theory approach to the study of body image concerns, self-presentation and selfperceptions in a sample of aerobic instructors. Journal of Health Psychology, 12(2), 301-315. https://doi.org/10.1177/1359105307074267

Van den Broeck, A., Ferris, D. L., Chang, C., \& Rosen, C. (2016). A review of selfdetermination theory's basic psychological needs at work. Journal of Management, 42(5), 1195-1229. https://doi.org/10.1177/0149206316632058

Vansteenkiste, M., \& Ryan, R. M. (2013). On psychological growth and vulnerability: Basic psychological need satisfaction and need frustration as a unifying principle. Journal of Psychotherapy Integration, 23(3), 263-280. https://doi.org/10.1037/ a0032359

Wininger, S. (2002). Instructors' and classroom characteristics associated with exercise enjoyment by females. Perceptual and Motor Skills, 94(2), 395-398. https://doi.org/10. 2466/pms.2002.94.2.395

\section{Author Biographies}

Filipe Rodrigues is a researcher at the CIEQV and lecturer at Sports Science School of Rio Maior (ESDRM - IPSantarém) and his research focuses on motivational and cognitive theories to understand health-related behavior change in diverse domains. Other areas of research interest include health psychology, interpersonal behaviors, coaching and neuropsychology.

Rita Macedo is a researcher in the field of social sciences, focusing on health-related outcomes and correlates of cultural differences. Her areas of interest are green product purchase, environmental and health concerns as well as the determinants of positive psychological consequences. 